\title{
Making Sense of Hydrosocial Patterns in Academic Papers on Extreme Freshwater Events
}

\author{
Alison Sammel \\ School of Education and Professional Development, Griffith University \\ Queensland, Australia \\ Lana D. Hartwig \\ Australian Rivers Institute and School of Environment \& Science, \\ Griffith University \\ Queensland, Australia
}

\section{Abstract}

This paper will communicate the outcomes of a systematic quantitative literature review that investigated how extreme freshwater events (EFWE) such as floods, droughts, and heavy rainfall are framed in peer-reviewed academic literature focusing on Queensland, Australia, and Saskatchewan, Canada. From this exercise, patterns emerge revealing a predominately science-based hydrological cycle perspective of EFWE with little recognition of societal influences. We advocate for a reframing of EFWE research in these areas to acknowledge how human practices are interconnected with the intensity and frequency of EFWE. We offer this study to encourage others to explore the contemporary narratives around EFWE emerging from research within their own locations.

Keywords: drought, extreme freshwater events, flood, heavy rainfall, hydrosocial cycle

\section{Introduction}

Extreme freshwater events (EFWE) include heavy rainfalls, floods and droughts. Even though EFWE occur naturally within global ecosystems, there is broad scientific consensus that with climate change, EFWE will intensify and become more frequent across the planet (Houngbo, 2018; Intergovernmental Panel on Climate Change [IPCC], 2014; Narula, 2018; World Water Assessment Programme [WWAP], 2012, 2014), influencing natural, non-human, and human systems

1 Corresponding author: a.sammel@griffith.edu.au. 
(IPCC, 2001, 2007). The consequences of EFWE, both positive and negative, vary greatly depending on the event location and duration, and vulnerability of the environment (IPCC, 2001; Panero, et al., 2018). From a human perspective, EFWE can result in loss of life (human and non-human), cause damage to property (flooding and heavy rainfall), destroy crops (threatening food security), contribute to health deterioration owing to waterborne diseases, and disrupt communication links and infrastructure such as electricity, transport, communication, education, and health care (IPCC, 2014). They can also disturb water catchments, affect storage reservoirs, affect the integrity of water treatment processes and distribution systems, and negatively impact regional water quality (Musavi et al., 2018; Strang, 2015; Wheater \& Gober, 2015). Additionally, loss of livelihoods and land values can leave individuals and communities economically vulnerable (MiddelmannFernandes, 2009). Changes to precipitation patterns can also increase the potential of wildfires, increase forest mortality, affect endemic species, and encourage invasive species (Goodess, 2013).

EFWE can also present beneficial consequences (Middelmann-Fernandes, 2009). Floodwaters soak into soils and replenish underground water stores, providing water supplies for agricultural crops and native plants (WWAP, 2014). Floodwaters can eliminate excess salts from soils, and excess waters can cause rivers to swell, removing debris and other pollution (WWAP, 2012). Further, many flora and fauna depend on EFWE cycles to connect habitats, offer alternative food sources, and trigger breeding, pollination, and seed dispersal (Apan et al., 2010). From a human perspective, this revitalization of ecosystems benefits tourism, the maintenance of recreational environments, and the subsequent economic benefits of increased flora or fauna production (Apan et al., 2010).

The factors, causes, and influences of EFWE are complex: probably more complex than we can currently imagine. Understanding the intricacies of EFWE will be influenced by how social systems investigate and make sense of these events. In this way, research plays a role in shaping how societies understand and respond to EFWE. This paper defines research as "any form of discipline inquiry that aims to contribute to a body of knowledge" (Economic and Social Research Council, 2005, p. 7). Academic research, more specifically, speaks to the construction of knowledge that emerges from verifiable, evidence-based research articles published in credible, academic, peer-reviewed journals. Globally, there has been an increase in the publication of academic articles offering research-based evidence on nearly every concept imaginable, including EFWE (Krause \& Strang, 2016). Indeed, as freshwater is essential to all life on this planet, nearly every academic discipline area investigates water in one way or another (Krause \& Strang, 2016; Strang, 2004). These individual academic articles offer specific knowledge around defined situations that add to our understandings of EFWE. By investigating this emerging knowledge base as a collective, it is possible to identify the contemporary narratives and patterns 
that derive from the accumulation of this knowledge. As such, this paper presents the findings of a systematic analysis of academic, peer-reviewed journal articles published between 2013 and 2015 about EFWE in two geographical locations.

The timeframe and geographical location were chosen to coincide with the publication of academic articles stemming from significant EFWE that occurred in 2011 in both Queensland and Saskatchewan. These locations were chosen as they are familiar to the authors, as they have lived in one or both places and witnessed the varying freshwater patterns. More specifically, both locations experienced devastating EFWE within months of each other in 2011, providing a chance to compare how emerging academic articles explored these events and what narratives they offered. Therefore, this study is time and location specific. This paper does not propose that the analyzed documents are reflective of all academic articles about EFWE. Rather, this paper draws attention to patterns and trends emerging from this particular body of academic research, allowing for the identification of how EFWE are framed, discussed, and understood within published peer-reviewed academic articles found within these specific locations and timeframes. This identification gives rise to the possibilities and limitations of how this knowledge frames academic literature in order to encourage metanarrative reflections of how freshwater might be framed in the future. We hope that by offering this small case study, we might encourage others to explore contemporary narratives around EFWE emerging from research within their own locations.

\section{Framing of extreme freshwater events}

Historically, EFWE were conceptualized as natural hazards, with Mother Nature or God unleashing pain and suffering on humans (Mustafa, 2009). Mustafa (2009) suggests that with the advent of science, Western societies have predominantly come to understand EFWE as natural hazards that may be solved through the application of scientific knowledge and engineering solutions. Within this scientific framing, EFWE are predominantly understood by a hydrological cycle description: the shortages or excesses of groundwater, atmospheric, or surface water resulting from precipitation levels within specific regions (Global Water Partnership, 2000; Krause, 2014, 2016). A hydrological cycle perspective focuses on the chemical properties of water, the interaction of water with Earth's ecological systems, and how it moves on, through, and around the Earth (Linton, 2008, 2010; Linton \& Budds, 2014). Sivapalan et al. (2012) suggest this understanding implies that water is an abstract concept, independent of history or society, while Strang (2004, 2014) suggests this perspective invites an understanding that water can be owned, controlled, and managed. Schmidt $(2013,2014)$ suggests the hydrological cycle perspective reflects a common way people, governments, and businesses make sense of freshwater. Linton and Budds (2014) advocate that politically understanding water via the hydrological 
cycle is convenient for economic purposes as it allows water to be viewed as a discrete resource, one that can be "exploited and manipulated without explicit regard for the complexity of relations between water and ecosystem functions" (p. 113).

A purely hydrological cycle understanding of EFWE is being challenged by a hydrosocial cycle understanding (Linton, 2010; Sammel, 2014, 2016; Sammel \& McMartin, 2014; Sammel et al., 2018; Sivapalan et al., 2012). A hydrosocial cycle understanding encourages EFWE to be understood as dynamic fluctuations in the quantity and flow of water, where water movement aligns with larger natural and socially constructed rhythms that have different temporal beats (Krause, 2013; Linton, 2008, 2014; Linton \& Budds, 2014; Tortajada \& Biswas, 2018). This perspective recognizes the complex, long-term coevolution of human systems with freshwater systems, where humans have interacted with and changed the natural environment, thereby directly influencing EFWE, just as EFWE also influence social systems (Bates et al., 2008; McMartin et al., 2018; Sivapalan et al., 2012). It seeks to make sense of the interplay between natural and social systems, including economics and political priorities (Di Baldassarre et al., 2013; Schmidt, 2013). Krause and Strang (2016) provide insight by suggesting a hydrosocial perspective illustrates how "water flows are fashioned by a combination of topography, power relations, built infrastructure, institutional arrangements, property relations, money and market forces, ideologies, social networks and the properties of water itself" (p. 635). Bijker (2012) claims, "we live in water cultures," where water is "a crucial constituent of any society, including cases of excess, as in flooding, or drought, as in deserts; and cases of infrastructure, as in canals and cases of expertise, as in hydroimperialism, societies will be better understood when the role of water is the focus of analysis" (p. 626). This emphasizes Bakker's (2012) position that water is inherently political.

Interpretations or understandings of EFWE are indicative of social process, policies, and discourses, which can be understood along a continuum that is reflective of different ideologies. From one standpoint, EFWE can be viewed as disturbing what is assumed to be the normalcy of natural systems upon which social systems have been built (Strang, 2004). From another, EFWE may be viewed as an inevitable part of the circulation of freshwater within living, fluctuating systems which are deeply interconnected and influenced by human existence and practices (Christian \& Wong, 2017; Harvey \& Stocker, 2015; Krause, 2014, 2016; Krause \& Strang, 2016; Likens et al., 2009; McMartin et al., 2018; Sivapalan et al., 2012; Tortajada $\&$ Biswas, 2018). This continuum highlights theoretical positions underpinning these standpoints, but to what degree are these standpoints represented in peerreviewed journal articles written about the 2011 Queensland or Saskatchewan EFWE? What assumptions, expectations and recommendations are held within academic publications around these specific EFWE? The aim of this paper is to investigate these questions by identifying patterns and trends that emerge about the 
2011 Queensland or Saskatchewan EFWE from academic papers across disciplines. Being clear about these patterns may allow for greater reflection on how these societies make sense of EFWE.

\section{Methods}

The methodology of this study was an instrumental case study that recognizes the complexity within the wholeness and utility of the case (Punch, 2005). A case can be defined as a phenomenon within a bounded context and, in this study, was defined as peer-reviewed academic literature, across multiple disciplines, that discuss EFWE in the context of Queensland, Australia, and Saskatchewan, Canada, published from 2013 to 2015, inclusive. These two regions were chosen because both experienced record-breaking flooding in 2011; Queensland faced one of the most devastating floods in Australian history, with $78 \%$ of the state declared a natural disaster zone (Wright et al., 2013) while Saskatchewan (and Manitoba) endured a massive flooding event described as one of the five worst floods in Canadian history (CBC News, 2011). Both areas host over a million residents with similarities in governance, investment in science and technology, systems of weather forecasting, emergency warnings, and response measures. Similarities also extend to education systems, including university publication expectations (Sammel et al., 2018).

To identify recent scholarly literature that focused on EFWE in Queensland or Saskatchewan, we employed Pickering and Byrne's (2014) systematic quantitative literature review method. We systematically searched for peer-reviewed papers that (1) focused on EFWE situated within Queensland, Australia or Saskatchewan, Canada, and (2) were published in English. To identify relevant studies, we searched the titles, abstracts, and keywords of papers in three electronic databases (ProQuest-All Databases, Scopus, and Web of Science-Core Collection) using the following strategy:

(flood* OR drought* OR "extreme water event" OR "heavy rainfall" OR "extreme rainfall” OR "water disaster") AND (Saskatchewan OR Queensland OR Brisbane)

Types of EFWE were used as search terms because "EFWE" is not an established concept in the literature. "Brisbane" was included as a search term in addition to "Queensland," given that the 2011 flooding event is sometimes referred to as the "Brisbane floods." Our search parameters limited retrieved papers to those published between 2013 and 2015 to collect recent literature and to coincide with the publication of academic articles stemming from significant 2011 EFWE in both Queensland and Saskatchewan. See Table 1 for a breakdown of search results. 
Table 1: Breakdown of search results.

\begin{tabular}{|l|c|}
\hline Detail & $\mathbf{n}$ \\
\hline Number of records identified through database searching & 555 \\
\hline Number of records after duplicates removed & 388 \\
\hline $\begin{array}{l}\text { Number of records after full-text articles assessed for eligibility, and included } \\
\text { in quantitative synthesis }\end{array}$ & 193 \\
\hline
\end{tabular}

Source: Authors' summary of research process.

As we were interested in characterizing how EFWE are framed and discussed in academic literature, it was essential that all papers focusing on such events, regardless of the research angle or approach, were retained. Some papers examined specific EFWE in Queensland and Saskatchewan, while others were concerned with possible EFWE in the future, taking a modeling or prediction-based approach.

Search results were screened to ensure each paper met this priority. The following criteria were used to determine if each should be included or excluded for analysis. Articles were excluded where the events or conditions examined were described as seasonal or regular, and therefore of minor significance (i.e., not considered extreme). For papers concerned with EFWE in multiple locations, a significant portion of the paper (which we determined to be at least one third) must have concerned Queensland or Saskatchewan to be included. Papers that discussed drought or flood as a characteristic of fauna or flora species were excluded. Finally, any results that focused mostly on marine-based events, such as flood tides, were excluded as our investigation concerned freshwater events only. Papers that examined impacts to marine systems as a result of EFWE, however, such as flood plumes in coastal marine ecosystems, were included.

The final set of papers ( $n=193)$ was coded for journal discipline, location of research, and type of EFWE discussed. Journal disciplines were determined using information retrieved from individual journal websites, including where journals self-identified as multidisciplinary. This was used to gain an indication only of likely discipline(s) for each paper. Two coding exercises were developed to facilitate characterizing how EFWE were framed within the reviewed literature. The first exercise recorded the dominant negative and positive EFWE-related concepts discussed in each paper. Table 2 presents the negative and positive coding categories and subcategories we developed based on recurring themes in the literature. As some of the reviewed papers examined more than one of these categories, where necessary we coded for the most focused-upon concepts across positive and negative concepts (up to five subcategories were observed). Where papers did not discuss any explicitly positive or negative concepts, these were coded as "neutral." 


\section{Table 2: Coding categories and subcategories for negative and positive concepts discussed in the analyzed papers.}

\begin{tabular}{|c|c|}
\hline Coding category & Coding subcategory \\
\hline \multicolumn{2}{|l|}{ Negative concepts } \\
\hline Economic concepts & $\begin{array}{l}\text { A-Financial costs to individuals, families, communities, businesses, } \\
\text { industries or sectors, organizations, and/or governments associated } \\
\text { with EFWE } \\
\text { B-Costs to businesses, industries, sectors, or economies due to } \\
\text { EFWE-associated impacts to infrastructure } \\
\text { C-Engineering and technology costs and damages associated with } \\
\text { EFWE }\end{array}$ \\
\hline $\begin{array}{l}\text { Societal or community } \\
\text { concepts }\end{array}$ & $\begin{array}{l}\text { D-Socio-emotional distress at a community level } \\
\text { E-Damage to or inefficacy of relations between individuals, families, } \\
\text { and/or communities during or after EFWE } \\
\text { F-Social infrastructure and services impacted or altered by EFWE } \\
\text { G-Unequal experiences of EFWE by different social groups } \\
\text { (e.g., vulnerable or marginalized communities) } \\
\text { H-Poor, low, or ineffective risk perception and behavioral responses } \\
\text { associated with EFWE }\end{array}$ \\
\hline $\begin{array}{l}\text { Planning, preparedness, } \\
\text { and response-based } \\
\text { concepts }\end{array}$ & $\begin{array}{l}\text { I-Overreliance on one component of planning or protection from EFWE } \\
\mathrm{J} \text {-Issues with planning for, management, response, and communication } \\
\text { of information before, during, or after EFWE } \\
\text { K-Focus on developing or evaluating specific measures to predict, plan } \\
\text { for, or monitor EFWE } \\
\text { L-Governance issues (e.g., law, land-use planning provisions, } \\
\text { government responsibilities, leadership) associated with planning for } \\
\text { or responding to EFWE }\end{array}$ \\
\hline $\begin{array}{l}\text { Health and wellbeing } \\
\text { concepts }\end{array}$ & $\begin{array}{l}\mathrm{M} \text {-Physical human health matters in relation to EFWE } \\
\mathrm{N} \text {-Emotional or psychological human health matters in relation to EFWE }\end{array}$ \\
\hline $\begin{array}{l}\text { Ecosystem or natural } \\
\text { environment concepts }\end{array}$ & $\begin{array}{l}\text { O-Temporary or permanent impacts or changes to species or } \\
\text { ecosystem function associated with EFWE } \\
\text { P-Focus concerns climatic attributes and weather patterns associated } \\
\text { with EFWE (e.g., El Niño, La Niña) } \\
\text { Q-Significant changes to the landscape associated with EFWE }\end{array}$ \\
\hline \multicolumn{2}{|l|}{ Positive concepts } \\
\hline $\begin{array}{l}\text { Societal or community } \\
\text { concepts }\end{array}$ & $\begin{array}{l}\text { R-Community growth or cohesion enhanced by EFWE } \\
\text { S-Support offered by stakeholders (including governments, } \\
\text { organizations, or individuals) in relation to EFWE } \\
\text { T-New social development opportunities arisen due to EFWE }\end{array}$ \\
\hline $\begin{array}{l}\text { Ecosystem or natural } \\
\text { environment concepts }\end{array}$ & $\begin{array}{l}\text { U-Benefits to ecosystems, environmental processes, or individual } \\
\text { species due to EFWE } \\
\text { V-EFWE offset or reduced significance of environmental impacts }\end{array}$ \\
\hline Other & Any other positive concepts discussed, with details noted \\
\hline
\end{tabular}

Note: $\mathrm{EFWE}=$ extreme freshwater events.

Source: Authors' summary of research process. 
The second coding exercise was designed to characterize how EFWE were framed within the collected literature, underpinned by the framing of EFWE discussion earlier in this paper. We established a four-point scale for this coding exercise. Papers that framed EFWE as exclusively natural events were categorized as Level 1, while papers that consistently framed EFWE as an inseparable component of society were categorized as Level 4. Table 3 presents a summary of characteristics for each scale point used to guide paper categorization. For this coding exercise, papers were coded into only one of the four categories, based on their dominant framing and depiction of EFWE.

\section{Table 3: Scale levels developed to characterize the framing of EFWE within literature as part of nature or society.}

\begin{tabular}{|c|c|}
\hline Scale level & Description and characteristics \\
\hline Level 1 & $\begin{array}{l}\text { Science-constructed framing or understanding of EFWE completely separate } \\
\text { from nature and society: } \\
\text { - Underpinning ideology views water as purely scientific, where water can be } \\
\text { understood as being limited or in excess as it moves on, through, and around } \\
\text { the Earth; } \\
\text { - Water and EFWE are understood as a "natural force" and "natural events" that } \\
\text { cannot be managed or controlled (separate and distinct from human systems); } \\
\text { - Water is framed as a resource, independent of social interactions that can be } \\
\text { owned, controlled and managed. }\end{array}$ \\
\hline Level 2 & $\begin{array}{l}\text { Predominantly science-constructed framing of EFWE as physical or natural } \\
\text { processes with minimal acknowledgment of connection to society: } \\
\text { - Underpinning ideology aligns with the hegemonic view that EFWE disturb what is } \\
\text { assumed to be the normalcy of natural systems upon which social systems have } \\
\text { been built; } \\
\text { - Focuses on the scientific occurrences of EFWE and their interactions with } \\
\text { other "natural" or environmental-based processes (separate and distinct from } \\
\text { human systems); } \\
\text { - Where societal aspect(s) are discussed, these tend to concern the impact or } \\
\text { aftermath of EFWE to society. Accordingly, EFWE are framed as "disasters" and } \\
\text { "crises" that cause major disruption and negative consequences for social and } \\
\text { - economic systems and priorities, reflective of an anthropocentric perspective; } \\
\text { Does not recognize many historical or complex underlying human societal attributes } \\
\text { that may have contributed to or influenced EFWE. Include minimal discussion of } \\
\text { management or preparedness. }\end{array}$ \\
\hline Level 3 & $\begin{array}{l}\text { Acknowledges the interconnection of hydrological and societal factors in EFWE, } \\
\text { though often with an emphasis on controlling and predicting EFWE through } \\
\text { engineering-based management "solutions": } \\
\text { - Underpinning ideology the same as Level 2, but has an added focus on management, } \\
\text { planning, and preparedness for EFWE. EFWE are discussed in terms of avoidance, } \\
\text { reduction, or mitigation of negative EFWE consequences to human societies; } \\
\text { - Focuses on the occurrences of EFWE and their interactions and interplay with } \\
\text { human societies, as well as natural or environmental-based systems; } \\
\text { - Recognizes EFWE impact societies, and societies may have contributed to } \\
\text { EFWE. While there may be a reflection that societies and EFWE are in some ways } \\
\text { interdependent, there are still instances of dualistic and separate understandings; } \\
\text { - May include some discussion that water shapes the landscape but no depth } \\
\text { of discussion that it also shapes human evolution - may include some minimal } \\
\text { theoretical links to this understanding but it is not the main message of the text. }\end{array}$ \\
\hline
\end{tabular}


Making Sense of Hydrosocial Patterns in Academic Papers on Extreme Freshwater Events

\begin{tabular}{|l|l|}
\hline Scale level & Description and characteristics \\
\hline Level 4 & Completely integrated understanding of EFWE as complexly interconnected with \\
& society, coevolving together through time: \\
& - Underpinning ideology focuses on EFWE as an inevitable part of the circulation of \\
& fresh water within living, fluctuating systems which are deeply interconnected and \\
& influenced by human existence and practices; \\
& - Does not offer purely scientific explanations of EFWE, and does not identify \\
& a natural/social dualism; \\
& EFWE are viewed as active agents of human evolution, and humans are not viewed \\
& as passive actors, but as contributing to and influencing EFWE; \\
& Include very specific examples of the political, economic, social or cultural elements \\
& of EFWE;
\end{tabular}

Note: EFWE = extreme freshwater events.

Source: Authors' summary of research process.

\section{Results}

In total, we reviewed 193 recently published papers of which 174 (90\% of total papers) concerned EFWE in Queensland, Australia and 19 (10\% of total papers) concerned Saskatchewan EFWE (see Table 4). Many publications discussed more than one type of EFWE. The most commonly discussed EFWE across all papers was flood ( $82 \%$ of total papers), followed by extreme rainfall (35\% of total papers) and drought (24\% of total papers). Within Queensland literature, discussion of EFWE reflected a similar distribution with flood EFWE discussed most ( $85 \%$ of Queensland papers) followed by rainfall (37\% of Queensland papers) and drought (18\% of Queensland papers). Saskatchewan literature, however, revealed a greater emphasis on drought, discussed in $84 \%$ of Saskatchewan papers, followed by flood (in $58 \%$ of Saskatchewan papers) and extreme rainfall (in $21 \%$ of Saskatchewan papers).

All 193 reviewed papers were published across a wide range of journal disciplines with hydrology and water engineering (51 papers, 26\%), ecology and conservation (45 papers, 23\%), and policy and government ( 43 papers, $22 \%$ ) the most common. Forty-six percent of papers (90 papers total) were retrieved from journals that self-identified as multidisciplinary. Queensland-based papers presented a similar distribution, while Saskatchewan-based literature was more dominated by hydrology and water engineering influences (42\%), and included fewer papers from multidisciplinary journals $(32 \%)$. 
Table 4: Summary of reviewed paper information and coded characteristics.

\begin{tabular}{|c|c|c|c|}
\hline Categories & $\begin{array}{l}\text { Total (\% of } \\
\text { total papers) }\end{array}$ & $\begin{array}{l}\text { Queensland } \\
\text { (\% of total QId } \\
\text { papers) }\end{array}$ & $\begin{array}{l}\text { Saskatchewan } \\
\text { (\% of total SK } \\
\text { papers) }\end{array}$ \\
\hline Total papers & 193 & $\begin{array}{l}174(90 \% \text { of all } \\
\text { papers) }\end{array}$ & $\begin{array}{l}19(10 \% \text { of all } \\
\text { papers) }\end{array}$ \\
\hline \multicolumn{4}{|l|}{ EFWE examined* } \\
\hline Drought & $47(24 \%)$ & $31(18 \%)$ & $16(84 \%)$ \\
\hline Flood & $159(82 \%)$ & $148(85 \%)$ & $11(58 \%)$ \\
\hline Extreme rainfall & $68(35 \%)$ & $64(37 \%)$ & $4(21 \%)$ \\
\hline Other (cyclone rain, snow melt) & $27(14 \%)$ & $25(14 \%)$ & $2(11 \%)$ \\
\hline \multicolumn{4}{|l|}{ Journal disciplines* } \\
\hline Multidisciplinary & $90(46 \%)$ & $84(48 \%)$ & $6(32 \%)$ \\
\hline $\begin{array}{l}\text { Hydrology, oceanography, and water } \\
\text { engineering }\end{array}$ & $51(26 \%)$ & $43(25 \%)$ & $8(42 \%)$ \\
\hline Ecology and conservation & $45(23 \%)$ & $41(23 \%)$ & $4(21 \%)$ \\
\hline Other & $\begin{array}{l}\text { Policy and } \\
\text { government: } \\
43(22 \%) \\
\end{array}$ & $\begin{array}{l}\text { Policy and } \\
\text { government: } \\
42(24 \%) \\
\end{array}$ & $\begin{array}{l}\text { Geography: } \\
4(21 \%)\end{array}$ \\
\hline \multicolumn{4}{|c|}{ Negative and positive EFWE-related concepts discussed* } \\
\hline Address negative EFWE concepts & $174(90 \%)$ & $158(91 \%)$ & $18(95 \%)$ \\
\hline Address positive EFWE concepts & $34(18 \%)$ & $34(20 \%)$ & $0(0 \%)$ \\
\hline $\begin{array}{l}\text { Address negative and positive EFWE } \\
\text { concepts }\end{array}$ & $29(15 \%)$ & $29(17 \%)$ & $0(0 \%)$ \\
\hline Neutral (neither negative nor positive) & $14(7 \%)$ & $13(7 \%)$ & $1(5 \%)$ \\
\hline \multicolumn{4}{|c|}{ Framing of EFWE within literature as part of nature or society } \\
\hline Level 1 & $15(8 \%)$ & $13(7 \%)$ & $2(11 \%)$ \\
\hline Level 2 & 123 (64\%) & $113(65 \%)$ & $10(53 \%)$ \\
\hline Level 3 & $51(26 \%)$ & $47(27 \%)$ & $4(21 \%)$ \\
\hline Level 4 & $4(2 \%)$ & $1(1 \%)$ & $3(16 \%)$ \\
\hline
\end{tabular}

Note: * May exceed $100 \%$ as papers could be coded more than once for these categories.

$\mathrm{EFWE}=$ extreme freshwater events.

Source: Authors' summary of research.

As outlined, we used two coding exercises to characterize how papers framed EFWE. Figures 1 and 2 graphically present the outcomes of the first coding exercise, which captured the negative and positive EFWE concepts (defined in Table 2) emphasized in the reviewed papers. The darkest shaded rows in Figure 1 reveal that negative EFWE concepts were emphasized in nearly all reviewed papers (90\%) compared to positive EFWE concepts which were discussed in less than one fifth of total papers. Of the total 34 papers that addressed positive EFWE concepts, 29 also 
focused on negative EFWE concepts, meaning only 5 papers focused exclusively on positive EFWE concepts. About 14 papers (or $7 \%$ of total papers) were considered neutral as they emphasized neither negative nor positive concepts. Interestingly, positive EFWE-related concepts were not emphasized in any Saskatchewan papers (see Table 4).

Among the overarching concepts coded, Figure 1 reveals that negative economic concepts the most emphasized among the reviewed papers (in 89 papers), followed by negative societal and community concepts (in 65 papers), and ecosystem and negative environment concepts (in 59 papers). Interestingly, the least discussed negative concept (negative health and wellbeing concepts in 38 papers) was discussed in more papers than all of the accumulated positive EFWE concepts (in 34 papers). The most prevalent positive EFWE concept category within the literature was societal and community concepts (in 20 papers).

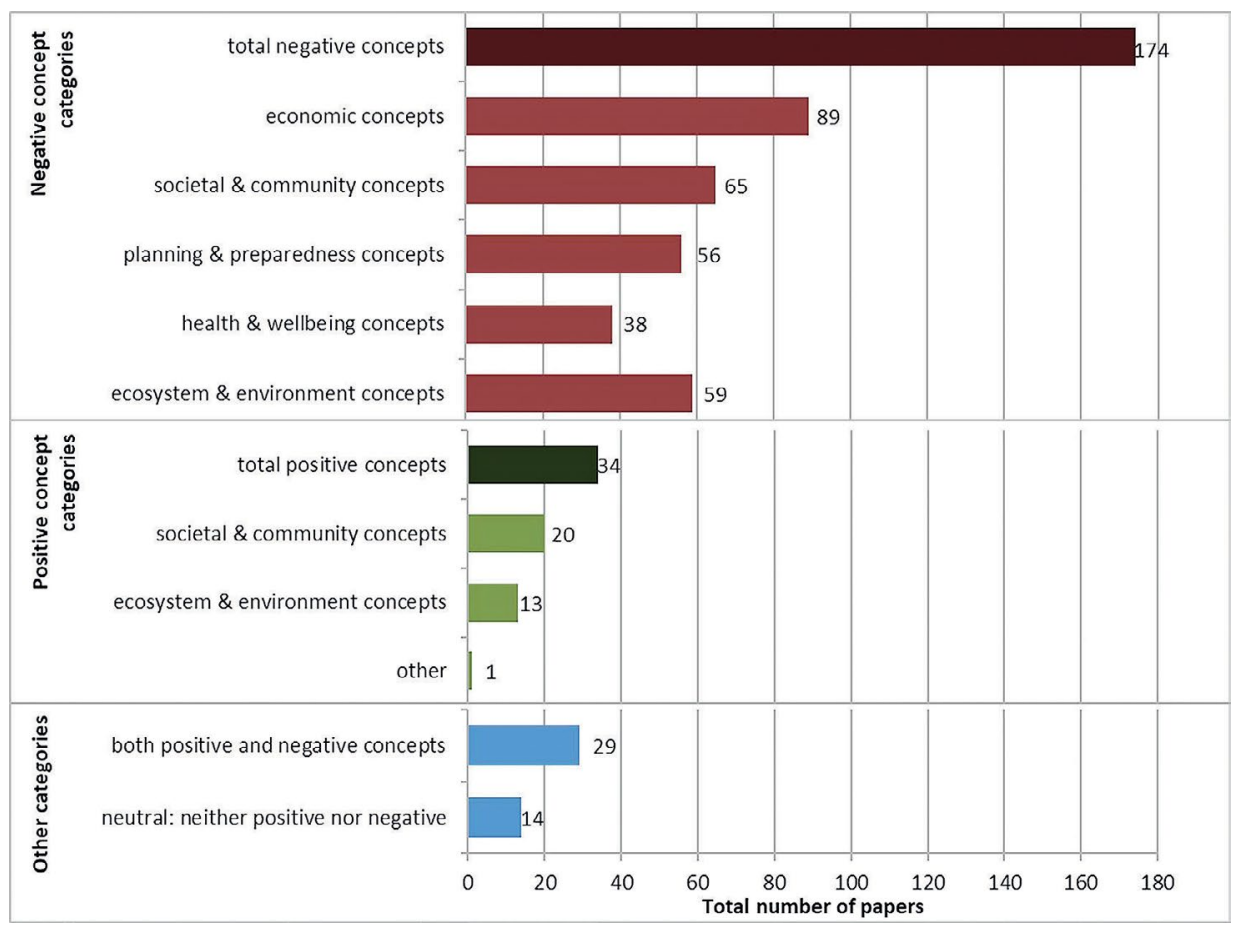

Figure 1: Breakdown of articles discussing negative and positive EFWE concepts.

Note: Total negative and total positive rows (shown by darkest shading) were calculated by totaling the number of papers coded as one or more of the constituting categories (shown in lighter shading).

Source: Authors' summary of research. 

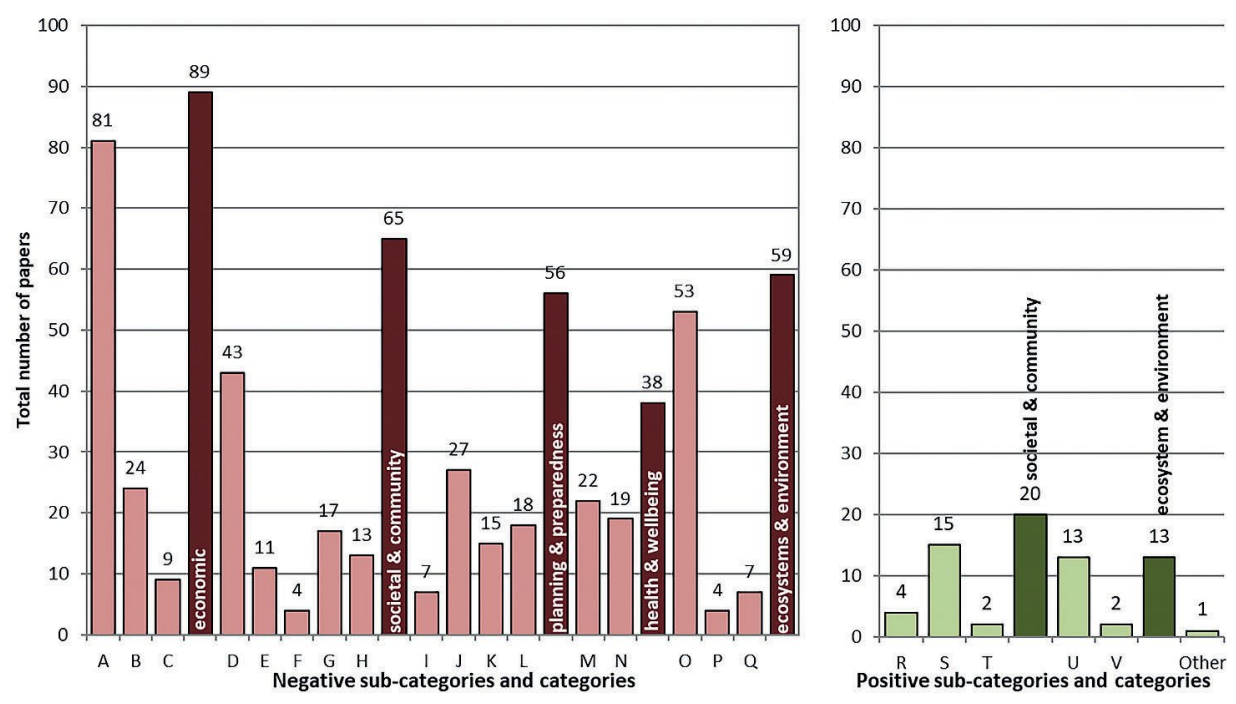

Figure 2: Breakdown of overarching negative and positive EFWE concepts. Note: See Table 2 for descriptions of each coding subcategory.

Source: Authors' summary of research.

Figure 2 provides further breakdown of the negative and positive EFWE concepts, presenting the number of papers that focused on each coding subcategory defined earlier in Table 2. For example, the total number of papers that emphasize negative economic concepts as shown in the fourth column of Figure 2 is the total number of papers that were coded for emphasizing one or more of the economic subcategories A, B, and/or C. Figure 2 shows that the most emphasized coding subcategory was A, which reflects an emphasis on the "discussion of financial costs to individuals, families, communities, businesses, industries, or sectors, organizations, and/or governments associated with EFWE" (from Table 2) in 81 total papers. The most prevalent positive subcategory was $S$, reflecting discussion about "support offered by stakeholders (including governments, organizations, or individuals) in relation to EFWE," coded in 15 papers.

The second coding exercise characterized how EFWE were framed in the papers using a four-point scale system from Levels 1 to 4 . Figure 3 demonstrates the overwhelming majority of papers (64\%) were categorized as Level 2. EFWE are predominantly understood, or portrayed, as science-constructed, physical, or natural processes with minimal acknowledgment of connection to society (as per Table 3). Papers coded as Level 3 comprised $26 \%$ of reviewed articles, while $8 \%$ were coded as Level 1 . Only 4 of the total 193 papers (2\%) were coded as Level 4 because they appeared to consistently frame EFWE as intricately, complexly, and inseparably interconnected with and to societies. Of these four publications, three are from Saskatchewan and one is from Queensland. 


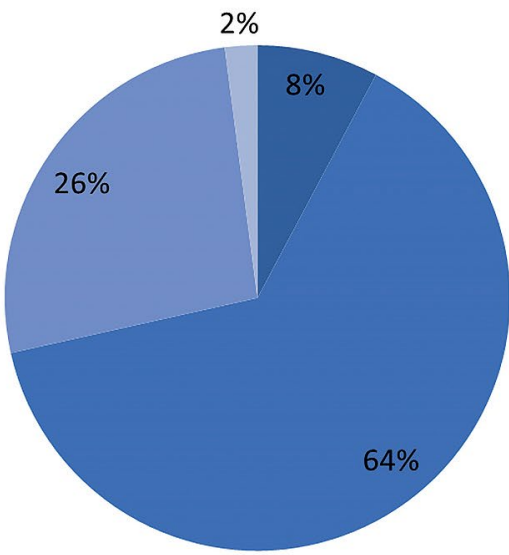

- Level 1-Science-constructed framing or understanding of EFWE completely separate from nature and society $[8 \%]$

- Level 2-Predominantly science-constructed framing of EFWE as physical or natural processes with minimal acknowledgment of connection to society [64\%]

- Level 3-Acknowledges the interconnection of hydrological and societal factors in EFWE, though often with an emphasis on controlling and predicting EFWE through engineering-based management "solutions" [26\%]

Level 4-Completely integrated understanding of EFWE as complexly interconnected with society, coevolving together through time [2\%]

Figure 3: Distribution of papers using scale levels developed to characterize the framing of EFWE within literature.

Source: Authors' summary of research.

\section{Discussion}

With the global freshwater landscape changing due to climate change (IPCC, 2014; WWAP, 2012, 2014), it becomes necessary to view the human-water relationship differently and investigate widely accepted paradigms and assumptions (Tortajada \& Biswas, 2018). Understanding the multiple geneses of emerging issues, identifying new and innovative approaches, and determining medium- and long-term implications is needed in order to reflect on present-day agendas. By investigating a contemporary narrative around EFWE in these specific academic articles, this paper adds to the growing conversation about EFWE by highlighting the need for academic papers to offer a balance of both hydrological and hydrosocial cycle perspectives within contemporary conversations. The results of this study show that $90 \%$ of all reviewed publications were classified as Level $2(64 \%)$ and $3(26 \%)$, as depicted by our developed four-point scale. This implies that the vast majority of academic articles frame EFWE within the hydrological cycle ideology which commonly views EFWE as natural disturbances in perceived normal quantities of water, viewing them as natural disasters or crises. This perspective is consistent with research advocating that water is dominantly interpreted as a natural resource, separate and distinct from human systems (Linton, 2008, 2010; Linton \& Budds, 2014; McMartin et al., 2018; Sammel et al., 2018; Schmidt, 2013, 2014; Sivapalan et al., 2012; Takao, 2016; Tortajada \& Biswas, 2018). Discussions of social aspects within Level 2 refer only to the impact or aftermath of EFWE to society, with little recognition of complex historical societal processes influencing EFWE. Papers within Level 2 focused on an anthropocentric agenda emphasizing negative aspects of EFWE with minimal discussion of management or preparedness. 
Interestingly, $90 \%$ is the same percentage of papers that also commented on the negative attributes of EFWE for humans. The most emphasized negative attributes were the consequences and disruptions for humans and societal infrastructure (financial costs to individuals, families, communities, businesses, etc.) and issues of socio-emotional distress at the community level. This is consistent with the assumption made by Di Baldassarre et al. (2013) that human civilizations have always settled near water in order to meet their basic needs (drinking water, agriculture, trade, and economic development) and as such, the occurrence of an EFWE can cause profound negative consequences for these societies. Understanding EFWE as negative, coupled with the need to mitigate against consequences, explains why papers classified as Level 3 were the second-most documented category. Level 3 papers focused on management, planning, or preparedness for EFWE as a means to avoid, reduce, or mitigate negative EFWE consequences to human societies. Krause (2016) suggests that in research and policy development there has been a shift from reacting to managing EFWE. Linton and Budds (2014) perceive the management of water to be a core component of the hydrological cycle. They believe it legitimizes the technical authority over water, where experts with scientific and technical knowledge can modify the movement of water for the benefit of human systems without acknowledging the wider relationship between humanity and the environment. A few Level 3 papers reflected on specific human-made changes to landscapes, commenting that these changes many have worsened the impacts from EFWE, but the impact of other human policies or actions were not acknowledged. Our results highlighted that EFWE were mostly commonly understood as "catastrophic natural process," as found in Smith et al. (2013, p. 416). This aligns with Mustafa's (2009) suggestion that Western societies predominantly understand EFWE as "natural" hazards to be solved through the application of scientific knowledge and engineering solutions. Papers categorized as Level 2 or 3 inherently understand humans as being at the mercy of EFWE, underpinned by a dualistic theme within the hydrological cycle perspective where nature and society are viewed separately.

Of the remaining papers, $8 \%$ were considered to be Level 1 . Papers within this category emphasize a purely science-constructed framing of EFWE, with a focus on how water moves on, through, and around the Earth. They suggest EFWE are "of nature" and so cannot be controlled, as they exist outside of, and independent to, society. This position completely separates water from social relationships.

This perspective is contrary to the $2 \%$ of papers that were coded as Level 4 . The hydrosocial ideology underpinning papers classified as Level 4 views EFWE as an inevitable part of the circulation of freshwater within living, fluctuating systems which are deeply interconnected with and influenced by human existence and practices. For example, one of the four papers in this category (Gober \& Wheater, 2014) discussed the pressures on the Saskatchewan River Basin, based upon Sivapalan et al. (2012) belief of the coupled coevolution of water and humans, where "it is not 
possible to predict water cycle dynamics over decadal or longer time periods without considering interactions and feedbacks among natural and human components of the water system" (Gober \& Wheater, 2014, p. 1419). Laforge and McLeman (2013), another of these four papers, discussed the coevolution of Saskatchewan and freshwater, through the role drought played in shaping and limiting the migration of people, and the impact of freshwater at the household level. Publications in this level offered a framing of EFWE where natural systems and societal systems-including politics, economics, spirituality, and power relations-were recognized as deeply interdependent and inseparable.

This Level 4 perspective aligns with Krause's (2016) argument that hydrosocial cycle perspectives invite us to view the circulation of water as an aspect of everyday social relations so we can understand how the temporal and spatial dynamics of water contribute to, and participate in, shaping social relations. In other words, the hydrosocial cycle perspective invites us to consider how over time, human processes influence our relationship with water, which in turn changes water's relationship with us through the simple expansion of water onto dry land, or the movement of water away from dry land. This perspective recognizes the limits of a hydrological cycle frame and asks societies to adopt an integrated perspective of water-human relationships so we can see the influence of human assumptions, values, understandings, and practices on how we frame our relationships with EFWE (Bakker, 2012; Bates et al., 2008; Gober \& Wheater, 2014; Krause, 2014, 2016; Krause \& Strang, 2016; Sammel, 2016; Sammel et al., 2018; McMartin et al., 2018; Sivapalan et al., 2012). Lindon and Budds (2014) warn of privileging the hydrological cycle perspective:

[it] is not merely a neutral scientific concept, but can be regarded as a social construct with political consequences ... that it emerged in a specific historical context in pursuit of particular objectives and interests, and that it was constructed according to a vision of nature that authorizes the realization of these objectives and interests by deploying a particular form of expertise. (p. 171)

Yet, our research reveals that in this reviewed collective body of academic work, this Level 4 perspective was rare, despite the United Nations' repeated calls for a more integrated approach to understand water-social relationships (Swyngedouw, 2006).

The privileging of the hydrological cycle within the reviewed academic papers presents opportunities to observe and reflect on Foucault's (1983) concept of regimes of truth. This concept suggests that within all societies, historical evolving patterns of thought, classifications, and forms of knowledge, have become so normalized that they structure society's perceptions of self and the world around them. This perceived legitimate knowledge holds so much power that it functions as the truth in that social system. And like any other concept, the "truth" about EFWE becomes so entrenched in social systems that it has the potential for controlling conversations. 
Even though our findings, based on literature pertaining to specific geographical areas, may not be representative of research literature from other geographical areas, they still do offer one conceptualization of a grand narrative of how multidisciplinary research frames understandings of EFWE. With this as a starting point, we ask, to what degree has the hydrological cycle perspective influenced what people believe to be "true" about EFWE? To what degree does this understanding limit or close down conversations about EFWE? How might a hydrological-focused perspective disable hydrosocial considerations, or other perspectives, such as considerations of EFWE from the perspectives of the more-than-human world? In asking these questions, we can't help but reflect upon the patterns and trends emerging from these specific peer-reviewed academic papers, and how they may exclude a wide net of perspectives, from many unique angles, or how they may limit our understanding of synergies between freshwater and the Earth itself.

\section{Conclusions}

Globally, humans (as well as the non-humans with whom we share this planet) face a future of unsustainable freshwater use and increased exposure to EFWE (Wheater \& Gober, 2015). Undeniably, there is urgent need to improve our understandings of natural and social systems that influence freshwater and EFWE. This study contributes to the literature by illustrating how recent academic research articles, in two geographical areas, dramatically privilege a hydrological cycle understanding of EFWE. Inherent within our findings is a negative, anthropocentric bias, where EFWE are assumed to be only natural events (separate and distinct from human systems) that can, and should, be managed to decrease disruptions to social systems and infrastructure. There is little acknowledging of historical, complex, coevolving relationships that humans have with freshwater. Based on our findings, we advocate for these geographical locations to employ more research from a hydrosocial cycle perspective-where EFWE are understood as an integrated and inevitable part of the circulation of freshwater, critical for all life, and deeply interconnected and influenced by human existence and practices.

Although this case study is small in scope, the pattern it identifies might be reflective of other research in other locations. As such, we strongly encourage researchers, in many geographical regions, to investigate what knowledge predominates (or has become normalized or legitimized) within broader EFWE narratives. We encourage this analysis to ensure balanced representations of hydrological and hydrosocial perspectives within academic research. This recommendation is made with the aim of generating greater depth and breadth of knowledge to assist people, including policy-makers, to more holistically recognize and address changing water conditions that will likely affect all life on our planet. 


\section{References}

Apan, A., Keogh, D. U., King, D., Thomas, M., Mushtaq, S., \& Baddiley, P. (2010). The 2008 floods in Queensland: A case study of vulnerability, resilience and adaptive capacity. Gold Coast, Australia: National Climate Change Adaptation Research Facility. doi.org/ $10.1007 /$ s11069-011-9791-y.

Bakker, K. (2012). Water: Political, biopolitical, material. Social Studies of Science, 42(4), 616-623. doi.org/10.1177/0306312712441396.

Bates, B. C., Kundzewicz, Z. W., Wu, S., \& Palutikof, J. P. (Eds.). (2008). Climate change and water: Technical paper of the Intergovernmental Panel on Climate Change. Geneva, Switzerland: IPCC.

Bijker, W. E. (2012). Do we live in water cultures? A methodology commentary. Social Studies of Science, 42(4), 624-627. doi.org/10.1177/0306312712441690.

CBC News. (2011, June 20). Floods displace hundreds in Saskatchewan. CBC News. Retrieved from www.cbc.ca/news/canada/saskatchewan/floods-displace-hundreds-insaskatchewan-1.1008834.

Christian, D., \& Wong, R. (2017). Downstream: Reimagining water. Waterloo, Canada: Wilfrid Laurier University Press.

Di Baldassarre, F., Viglione, A., Carr, G., Kuil, L., Salinas, J. L., \& Blöschl, G. (2013). Socio-hydrology: Conceptualising human-flood interactions. Hydrology and Earth System Sciences, 17(8), 3295-3303. doi.org/10.5194/hess-17-3295-2013.

Economic and Social Research Council (ESRC). (2005). Research ethics framework. Swindon, UK: ESRC.

Foucault, M. (1983). The subject and power. In H. L. Dreyfus \& P. Rabinow (Eds.) Michel Foucault: Beyond structuralism and hermeneutics, 2nd Edition (pp. 208-226). Chicago, US: University of Chicago Press. doi.org/10.1086/ahr/88.3.648.

Global Water Partnership. (2000). Towards water security: A framework for action. Stockholm, Sweden: Global Water Partnership.

Gober, P., \& Wheater, H. S. (2014). Socio-hydrology and the science-policy interface: A case study of the Saskatchewan River Basin. Hydrology and Earth System Sciences, 18(4), 1413-1422. doi.org/10.5194/hess-18-1413-2014.

Goodess, C. M. (2013). How is the frequency, location and severity of extreme events likely to change up to 2060? Environmental Science \& Policy, 27, S4-S14. doi.org/10.1016/ j.envsci.2012.04.001.

Harvey, N., \& Stocker, L. (2015). Coastal residential waterways, science and policy-making: The Australian experience. Estuarine, Coastal and Shelf Science, 155, A1-A13. doi.org/ 10.1016/j.ecss.2014.12.019. 
Houngbo, G. F. (2018). The role of UN-water as an inter-agency coordination mechanism for water and sanitation. UN Chronicle, 55(1), 19-21. Retrieved from unchronicle. un.org/article/role-un-water-inter-agency-coordination-mechanism-water-and-sanitation. doi.org/10.18356/e9d755fa-en.

Intergovernmental Panel on Climate Change (IPCC). (2001). Climate change 2001: Impacts, adaptation and vulnerability. Contribution of Working Group II to the Third Assessment Report of the Intergovernmental Panel on Climate Change. Cambridge, UK: Cambridge University Press. doi.org/10.1080/01944363.2014.954464.

Intergovernmental Panel on Climate Change (IPCC). (2007). Climate change 2007: The physical science basis. Contribution of Working Group I to the Fourth Assessment Report of the Intergovernmental Panel on Climate Change. Cambridge, UK: Cambridge University Press. doi.org/10.1017/cbo9781107415324.023.

Intergovernmental Panel on Climate Change (IPCC). (2014). Climate Change 2014: Synthesis Report. Contribution of Working Groups I, II and III to the Fifth Assessment Report of the Intergovernmental Panel on Climate Change. Geneva, Switzerland: IPCC. doi.org/ 10.1017/cbo9781107415416.

Krause, F. (2013). Seasons as rhythms on the Kemi River in Finnish Lapland. Ethnos, 78(1), 23-46. doi.org/10.1080/00141844.2011.623303.

Krause, F. (2014). Reclaiming flow for a lively anthropology. Suomen Antropologi: Journal of the Finnish Anthropological Society, 39(2), 89-102.

Krause, F. (2016). “One man's flood defense is another man's flood": Relating through water flows in Gloucestershire, England. Society \& Natural Resources, 29(6), 681-695. doi.org/ 10.1080/08941920.2015.1107787.

Krause, F., \& Strang, V. (2016). Thinking relationships through water. Society \& Natural Resources, 29(6), 633-638. doi.org/10.1080/08941920.2016.1151714.

Laforge, J. M., \& McLeman, R. (2013). Social capital and drought-migrant integration in 1930s Saskatchewan. The Canadian Geographer, 57(4), 488-505. doi.org/10.1111/ j.1541-0064.2013.12045.x.

Likens, G. E., Walke, K. F., Davies, P. E., Brookes, J., Olley, J., Young, W. J., Thomas, M. C., Lake, P. S., Gawne, B., Davis, J., Arthington, A. H., Thompson, R., \& Oliver, R. L. (2009). Ecosystem science: Towards a new paradigm for managing Australia's inland aquatic ecosystems. Marine and Freshwater Research, 60(3), 271-279. doi.org/10.1071/ MF08188.

Linton, J. (2008). Is the hydrologic cycle sustainable? A historical-geographical critique of a modern concept. Annals of the Association of American Geographers, 98(3), 630-649. doi.org/10.1080/00045600802046619.

Linton, J. (2010). What is water? The history of a modern abstraction. Vancouver, Canada: UBC Press. 
Linton, J. (2014). Modern water and its discontents: A history of hydrosocial renewal. Wiley Interdisciplinary Reviews: Water, 1(1), 111-120. doi.org/10.1002/wat2.1009.

Linton, J., \& Budds, J. (2014). The hydrosocial cycle: Defining and mobilizing a relational-dialectical approach to water. Geoforum, 75, 170-180. doi.org/10.1016/ j.geoforum.2013.10.008.

McMartin, D., Sammel, A., \& Arbuthnott, K. (2018). Community response and engagement during extreme water events in Saskatchewan, Canada and Queensland, Australia. Journal of Environmental Management, 61(1), 34-45. doi.org/10.1007/s00267-017-0944-y.

Middelmann-Fernandes, M. H. (2009). Review of the Australian Flood Studies Database Geoscience. Australia Record 2009/34. Canberra, Australia: Geoscience Australia.

Musavi, M., Friess, W. A., Cary, J., \& Isherwood, J. C. (2018). Changing the face of STEM with stormwater research. International Journal of STEM Education, 5(2), 1-12. doi.org/ 10.1186/s40594-018-0099-2.

Mustafa, D. (2009). Natural hazards. In N. Castree, D. Demeritt, D. Liverman, \& B. Rhoads (Eds.), A companion to environmental geography (pp. 461-474). West Sussex, UK: Blackwell. doi.org/10.1002/9781444305722.

Narula, M. (2018). The dynamic role of gender and social inclusion achieving internationally agreed water-related goals. UN Chronicle, 55(1), 48-51. doi.org/10.1002/97814443 05722 .

Panero, M. A., Ashton, W. S., Izquierdo, C., Martin, M. H., \& Anid, N. M. (2018). Linking education to industry: Water and energy sustainability in Latin America. Journal of Environmental Studies and Sciences, 31(8), 1-14. doi.org/10.1007/s13412-018-0503-8.

Pickering, C., \& Byrne, J. (2014). The benefits of publishing systematic quantitative literature reviews for $\mathrm{PhD}$ candidates and other early career researchers. Higher Education Research and Development, 33(3), 534-548. doi.org/10.1080/07294360.2013.841651.

Punch, K. (2005). Introduction to social research: Quantitative and qualitative approaches. 2nd Edition. London, UK: Sage.

Sammel, A. (2014). A case study of water education in Australia. Creative Education, 5(13), 1148-1159. doi.org/10.4236/ce.2014.513129.

Sammel, A. (2016). Her beauty and her terror: A case study exploring the framing of water and extreme water events within formal education in Queensland, Australia and Saskatchewan, Canada. Geoforum, 76, 164-175. doi.org/10.1016/j.geoforum.2016.09.015.

Sammel, A. \& McMartin, D. (2014). Teaching and knowing beyond the water cycle: What does it mean to be water literate? Creative Education, 5(10), 835-848. doi.org/10.4236/ ce.2014.510097.

Sammel, A., McMartin, D., \& Arbuthnott, K. (2018). Education agendas and resistance with the teaching and learning of water and extreme water events. The Australian Journal of Environmental Education, 34(1), 18-32. doi.org/10.1017/aee.2018.10. 
Schmidt, J. J. (2013). Integrating water management in the Anthropocene. Society \& Natural Resources, 26(1), 105-112. doi.org/10.1080/08941920.2012.685146.

Schmidt, J. J. (2014). Historicising the hydrosocial cycle. Water Alternatives, 7(1), 220-234.

Sivapalan, M., Savenie, H. H. G., \& Blöschl, G. (2012). Socio-hydrology: A new science of people and water. Hydrologic Processes, 26(8), 1270-1276. doi.org/10.1002/hyp.8426.

Smith, A. G., McAlpine, C. A., Rhodes, J. R., Lunney, D., Seabrook, L., \& Baxter, G. (2013). Out on a limb: Habitat use of a specialist folivore, the koala, at the edge of its range in a modified semi-arid landscape, Landscape Ecology, 28, 415-426. doi.org/ 10.1007/s10980-013-9846-4.

Strang, V. (2004). The meaning of water. Oxford, UK: Berg.

Strang, V. (2014). Fluid consistencies: Material relationality in human engagements with water. Archaeological Dialogues, 21(2), 133-150. doi.org/10.1017/s1380203814000130.

Strang, V. (2015).Water: Nature and culture. Chicago, US. Reaktion Books/University of Chicago Press.

Swyngedouw, E. (2006). Power, water and money: Exploring the nexus. Human Development Report Office Occasional Paper 2006/14. Oxford, UK: Oxford University and United Nations Development Programme.

Takao, Y. (2016). Making environmental policy work with civic science: The intermediary role of expert citizens at the Japanese local level. Local Environment, 21(9), 1100-1117. doi.org/10.1080/13549839.2015.1070335.

Tortajada, C., \& Biswas, A. K. (2018). Impacts of megatrends on the global water landscape. International Journal of Water Resources Development, 34(2), 147-149. doi.org/10.1080/ 07900627.2018.1429905.

Wheater, H. S., \& Gober, P. (2015). Water security and the science agenda. Water Resources Research, 51(7), 5406-5424. doi.org/10.1002/2015WR016892.

World Water Assessment Programme (WWAP). (2012). The United Nations world water development report 4: Managing water under uncertainty and risk. Paris, France: UNESCO.

World Water Assessment Programme (WWAP). (2014). The United Nations world water development report 2014: Water and energy. Paris, France: UNESCO.

Wright, A. L., Nichols, E., McKechnie, M., \& McCarthy, S. (2013). Combining crisis management and evidence-based management: The Queensland floods as a teachable moment. Journal of Management Education, 37(1), 135-160. doi.org/10.1177/10525 62912455522. 
This text is taken from Human Ecology Review, Volume 25, Number 1, 2019, published by ANU Press, The Australian National University, Canberra, Australia. doi.org/10.22459/HER.25.01.2019.06 